Provided for non-commercial research and education use. Not for reproduction, distribution or commercial use.

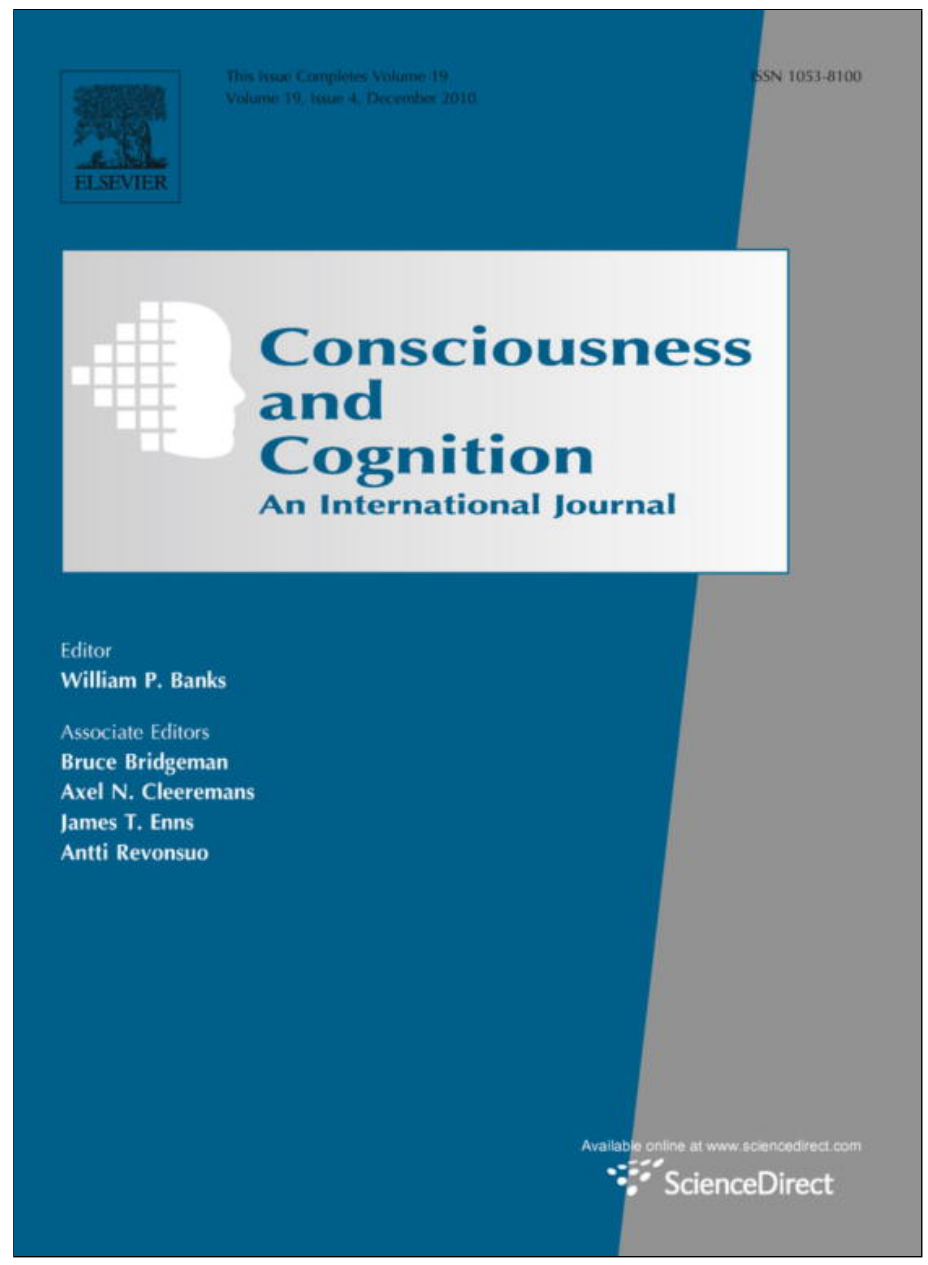

This article appeared in a journal published by Elsevier. The attached copy is furnished to the author for internal non-commercial research and education use, including for instruction at the authors institution and sharing with colleagues.

Other uses, including reproduction and distribution, or selling or licensing copies, or posting to personal, institutional or third party websites are prohibited.

In most cases authors are permitted to post their version of the article (e.g. in Word or Tex form) to their personal website or institutional repository. Authors requiring further information regarding Elsevier's archiving and manuscript policies are encouraged to visit:

http://www.elsevier.com/copyright 


\title{
What subjective experiences determine the perception of falling asleep during sleep onset period?
}

\author{
Chien-Ming Yang ${ }^{\mathrm{a}, \mathrm{b}, *}$, Huei-Ya Han ${ }^{\mathrm{c}}$, Ming-Hsin Yang ${ }^{\mathrm{a}}$, Wei-Chen Su ${ }^{\mathrm{a}}$, Timothy Lane ${ }^{\mathrm{b}}$ \\ ${ }^{a}$ Department of Psychology, National Chengchi University, Taipei, Taiwan \\ ${ }^{\mathrm{b}}$ The Research Center for Mind, Brain, and Learning, National Chengchi University, Taipei, Taiwan \\ ${ }^{\mathrm{c}}$ Psychology Department, The University of Southern Mississippi, Hattiesburg, MS, USA
}

\section{A R T I C L E I N F O}

\section{Article history:}

Received 9 July 2009

Available online 25 January 2010

\section{Keywords:}

Sleep onset

Subjective experience

Perception of sleep

Depth of sleep

\begin{abstract}
A B S T R A C T
Sleep onset is associated with marked changes in behavioral, physiological, and subjective phenomena. In daily life though subjective experience is the main criterion in terms of which we identify it. But very few studies have focused on these experiences. This study seeks to identify the subjective variables that reflect sleep onset. Twenty young subjects took an afternoon nap in the laboratory while polysomnographic recordings were made. They were awakened four times in order to assess subjective experiences that correlate with the (1) appearance of slow eye movement, (2) initiation of stage 1 sleep, (3) initiation of stage 2 sleep, and (4) 5 min after the start of stage 2 sleep. A logistic regression identified control over and logic of thought as the two variables that predict the perception of having fallen asleep. For sleep perception, these two variables accurately classified $91.7 \%$ of the cases; for the waking state, $84.1 \%$.
\end{abstract}

(c) 2010 Elsevier Inc. All rights reserved.

\section{Introduction}

Sleep onset period is defined as the transition from relaxed, drowsy wakefulness to unresponsive sleep. It has been observed that this period is associated with marked changes in a host of physiological and behavioral phenomena, as well as in subjective experience (Ogilvie \& Wilkinson, 1984). Physiological phenomena associated with sleep onset include: decrease in high frequency electroencephalographic (EEG) activities (e.g., Azekawa, Sei, \& Morita, 1990; Davis, Davis, Loomis, Harvey, \& Hobart, 1937, 1938; Hori, 1985; Merica, Fortune, \& Gaillard, 1991; Rechtschaffen \& Kales, 1968; Tsuno et al., 2002); the absence and presence of different event-related potential (ERP) components (for review, see Campbell, Bell, \& Bastien, 1992; Harsh, Voss, Hull, Schrepfer, \& Badia, 1994); the appearance of slow eye movements (e.g., De Gennaro, Ferrara, Ferlazzo, \& Bertini, 2000; Porte, 2004); the absence of elicited skin conductance responses (e.g., Johnson, 1970); a drop in the core body temperature and an increase in the distal skin temperature (e.g., Barrett, Lack, \& Morris, 1993; Krauchi, Cajochen, Werth, \& Wirz-Justice, 2000; Wehr, 1990); and, substantial, rapid reduction in respiration (e.g., Colrain, Trinder, Fraser, \& Wilson, 1987; Naifeh \& Kamiya, 1981). Behavioral indicators of sleep onset include: a decrease in sensory threshold, a cessation of responses to external stimuli (e.g., Anliker, 1966; Ogilvie \& Simons, 1992; Ogilvie, Simons, Kuderian, MacDonald, \& Rustenburg, 1991; Ogilvie \& Wilkinson, 1984, 1988; Ogilvie, Wilkinson, \& Allison, 1989; Simon \& Emmons, 1956), and a decrease in muscle strength (e.g., Jacobson, Kales, Lehmann, \& Hoedemaker, 1964; Litchman, 1974) were also observed in the course of the sleep onset process. And, as regards the subjective experience of sleep onset, loss of awareness of environmen-

\footnotetext{
* Corresponding author. Address: Department of Psychology, National Chengchi University, 64, Sec. 2, Chih-Nan Rd., Taipei 116, Taiwan.

E-mail addresses: yangcm@nccu.edu.tw, dryangcm@gmail.com (C.-M. Yang).
} 
tal stimuli and the loss of control over thought processes have both been reported (e.g., Foulkes \& Vogel, 1965; Gibson, Perry, Redington, \& Kamiya, 1982).

Although these different phenomena are all associated with sleep onset, they are not always synchronized. Thus, the criteria for sleep onset identified for different studies are not consistent with one another. Most studies used physiological indices: for example, one of the most commonly used standards for sleep onset - the beginning of stage 1 sleep - is defined as the first 30-s epoch in which EEG alpha activities decrease to less than 50\% (Rechtschaffen \& Kales, 1968). Other studies, however, demonstrated that the subjective perception of falling asleep was more closely associated with stage 2 sleep, which is characterized by diminished responsivity to external stimuli. Webb (1980) reported that from $66.7 \%$ to $85 \%$ of those who were physically roused from sleep while in stage 2 sleep perceived this as awakening from sleep; the others did not feel as though they had been asleep. Even higher rates of discrepancy between physical arousal and the subjective perception of awakening were reported when assessments were made at the onset of stage 2 sleep: in several studies the percentage of those who felt as though they had been asleep was below 50\% (Amrhein \& Schulz, 2000; Hori, Hayashi, \& Morikawa, 1994; Sewitch, 1984).

Naturally physiological definitions of sleep onset lend themselves to stricter methodological controls. Thus, they tend to be accepted as the standard indices of sleep onset. It is commonly assumed that physiological indications of sleep highly correlate with subjectively experienced sleep. Discrepancies between the two tend to be regarded as "sleep-state misperception." Regarding this as a "misperception" clearly implies that physiological measures are given greater weight. In daily life, by contrast, subjective perception is the most frequently used criterion for sleep onset. People typically judge the amount of time taken to fall asleep merely on the basis of our subjective experience, without the evidence of any objective indices. Relatively few studies, however, have focused on the subjective experiences that reflect sleep onset. Although a few previous studies have examined the correspondence between subjective experience and electrophysiological phenomenon during sleep onset, to the best of our knowledge, no study has explored the subjective experience that determines the perception of sleep onset.

Previous studies revealed that subjective experiences occurring during sleep onset include changes in thoughts, images, or sensations (for review, see Schacter, 1976). For example, Foulkes and Vogel (1965) collected 212 reports on the subjective experience of sleep onset from nine, young and healthy subjects, at four distinct junctures: continuous alpha EEG with rapid eye movements (REMs), discontinuous alpha EEG with slow eye movements (SEMs), descent into stage 1 sleep, and 0.52.5 min of stage 2 sleep. The aspects of subjective experience analyzed included sensory imagery, affect, thought control, and reality orientation. Foulkes and Vogel reported that sensory experiences were primarily visual, and remained so throughout the sleep onset period. Thought control and reality testing were found to decrease continuously during the process of falling asleep. Affective experience was minimal to begin with and then decreased even more after one had fallen asleep. Foulkes and Vogel concluded that hypnagogic experience - defined as a state of intermediate consciousness that precedes sleep - was quite similar to REM dream experience. This same pattern of changes in subjective experience was confirmed in other studies by the same research group (Vogel, Barrowclough, \& Giesler, 1972; Vogel, Foulkes, \& Trosman, 1966). Similarly, Gibson and his colleagues investigated subjective experiences associated with judgments that corresponded to physiological sleep states during the sleep onset period. They discovered that three cognitive criteria were significantly correlated with correct estimation of physiological sleep states; these three were thought control, awareness of surroundings, and temporal awareness (Gibson et al., 1982). More recently, a study utilized the absence of eyelid and head movements to define sleep onset and collected over 1000 reports of subjective experience from 11 subjects sleeping at home. The results were similar to those of previous studies in that they evinced a decrease in "wake-like" thoughts and an increase in dreamlike mentations from 15 s to 5 min following sleep onset (Rowley, Stickgold, \& Hobson, 1998).

Furthermore, other studies used a more data-driven approach to identify the cluster of subjective experiences that are associated with physiologically defined sleep onset. For example, a study used canonical correlations to investigate the correspondences between EEG states and subjective experiences, with subjects lying in bed during their typical bedtime. Results showed that peak power in $2-6 \mathrm{~Hz}$ and $13-15 \mathrm{~Hz}$ bands as well as low power in $9-11 \mathrm{~Hz}$ and $16-25 \mathrm{~Hz}$ bands were associated with a cluster of subjective experiences. These experiences included the perception of falling asleep along with other perceptual and cognitive variables, such as altered reality-remoteness, low familiarity, sudden ideas without goal-orientation, and lack of body perception (Lehmann, Grass, \& Meier, 1995). Another study using principle component analysis identified a dimension of subjective experience that differentiated physiologically defined sleep states (stage 1 and stage 2) from waking states. The experiences that had the highest loading included the loss of awareness of the experimental situation, reported sleepiness, and inward directed attention (Wackermann, Pütz, Büchi, Strauch, \& Lehmann, 2002). Although these studies did examine subjective experience during sleep onset, their main concern was to compare dream mentation to sleep onset experience, or to search for associations between subjective experiences and EEG activity. They did not attempt to identify the subjective experiences that determine the perception of falling asleep.

Previous studies have consistently demonstrated that sleep onset processes are associated with a decrease in awareness of environmental stimuli and with diminishing thought control. But they have not clearly identified precisely what factors are involved with the perception that we have fallen asleep. The primary goal of the current study is to probe the subjective experiences that are critical to this perception. Subjects were awakened at several junctures during sleep onset, in order to identify the various subjective experiences involved. Regression analyzes were then conducted in order to tease out those experiences that are decisive in explaining perception of sleep onset. 


\section{Methods}

\subsection{Subjects}

Twenty-six subjects were recruited from a university campus, to participate in the study. Because six of them could not fall asleep after repeated awakenings, they were excluded from data analysis. Twenty subjects (nine males and 11 females), completed the procedures. Their mean age was 24.2 years, with a standard deviation of 3.24. The criteria for inclusion were: (1) age between 20 and 35 years; (2) no current or past major medical or psychiatric illnesses, and no evidence of sleep disorders; (3) no current use of prescribed or leisure drugs that might affect sleep; and (4) non-shift workers with regular sleepwake schedules. Potential subjects were screened for sleep, psychiatric, and major medical disorders in a clinical interview conducted by a trained, clinical psychology, graduate student.

\subsection{Procedure}

The subjects who satisfied the inclusion criteria were scheduled to arrive at the sleep laboratory, based in a university, for an afternoon-nap test. In order to enhance the likelihood that subjects would continue to fall asleep, even after repeated experimental awakenings during the nap, they were instructed to sleep $2 \mathrm{~h}$ less than usual during the night prior to their arrival at the laboratory. After obtaining the subjects' informed consent, electrodes were attached. While the electrodes were being positioned, the subjects were instructed to read through a list of questions that would be asked immediately after each awakening during the course of the experiment, questions used to assess their subjective experiences. The meaning of these questions was made clear to the subjects prior to the start of the experiment. Before beginning the nap test, the subjects were informed that an intercom system would be used to awaken them, and that their interview would be taken immediately afterward.

The recording montage for the polysomnography (PSG) included: an electroencephalogram (EEG), with electrodes placed at C3/A2, C4/A1, O1/A2, O2/A1; electrooculography (EOG) to measure left and right eye movements; chin electromyography (EMG); and electrocardiography (ECG). The impedances of all electrodes were kept below $5 \mathrm{k} \Omega$ prior to the start of recording. A total of five awakenings were conducted for each subject. The first awakening was a practice run, to familiarize the subjects with the procedures. It was conducted 2 min after the light was put out, regardless of whether the subject was in the wake state or sleep state. Data from the first awakening were not analyzed. The other four awakenings were conducted on the basis of different PSG features, which were as follows:

1. The emergence of a clear slow eye movement (SEM).

2. The onset of stage 1 sleep, defined as the first 30-s epoch in which EEG alpha activities decreased to less than $50 \%$ (S1).

3. The onset of stage 2 sleep, as defined by the emergence of a K-complex or a sleep spindle (S2)

4. A 5-min continuation of stage 2 sleep $(\mathrm{S} 2+5)$.

In order to avoid sequence effects, sequencing of the four awakening junctures was counter-balanced across all subjects. The awakening junctures were identified on-line by a well-trained graduate student and were independently confirmed by another well-trained graduate student.

Each time the subject was awakened, his or her name was called out through an intercom system. As soon as the ongoing EEG display indicated that the subject was fully awake, an experimenter entered the bedroom and conducted the interview while the subject lay in bed. During the interview the lights remained off, such that the room was just faintly illuminated by light from the adjacent monitoring room. The experimenter assessed the subject's perception of the sleep state through a structured questionnaire designed to probe various aspects of subjective experience. Questions were as follows:

\section{Perception of Sleep}

1-1. Sleep Perception: "Did you fall asleep?" $(\mathrm{Y} / \mathrm{N})$

1-2. Depth of Sleep: “How deep was your sleep?" (0-5)

2. Experiences of Sensation and Perception

2-1. Clarity of Environmental Perception: "How clearly were you able to perceive any environmental stimuli?" (0-5)

2-2. Visual Image: "Did you see any visual images?" $(\mathrm{Y} / \mathrm{N})$

2-3. Vividness of Visual Image: "How vivid was the visual image?" (0-5)

2-4. Auditory Perception: "Did you hear any sounds and/or voices?" ( $\mathrm{Y} / \mathrm{N})$

2-5. Clarity of Auditory Perception: "How clear were the sounds/voices?" (0-5)

2-6. Other Sensory Experiences: "Were there any other sensations such as bodily or olfactory sensations?" (Y/N)

2-7. Control over Perception: "Were you able to control your perceptual experiences?" (0-5)

4-1. Perceived Reality: "How real did any of the experiences seem to you?" (0-5) (This question is classified under Orientation and Involvement, but was located here on the questionnaire.) 
3. Thinking Processes

3-1. Thinking Experience: "Were you thinking of anything when I called out your name?" (Y/N)

3-2. Control over Thinking Process: "How well were you able to control your thoughts?" (0-5)

3-3. Coherence of Thinking Process: "How coherent was your thinking process?" (0-5)

3-4. Logic of Thinking Process: "Were your thoughts logical?" (0-5)

4-2. Daily-life concerns: "Were the thoughts related to your daily-life concerns?" (0-5) (This question is classified under Orientation and Involvement, but was located here on the questionnaire.)

4-3. Here-and-now experience: "Were the thoughts related to the situation in the lab?" (0-5) (This question is classified under Orientation and Involvement, but was located here on the questionnaire.)

4. Orientation and Involvement

4-4. Sense of Involvement: "Did you feel more like an observer (0), or did the thoughts and experiences seem to be yours (5)?" (0-5)

4-5. Orientation: "To what degree were you aware that you were in the lab and lying in bed?" (0-5)

5. Emotion

5-1. Emotional Experience: “Were you experiencing any emotion at the moment I called you?" $(\mathrm{Y} / \mathrm{N})$

5-2. Types of Emotion: "What type of emotion did you experience?"

5-3. Valence of Emotion: "Was the emotion positive or negative?"

5-4. Intensity of Emotion: "How intense was the emotion?" (0-5)

\section{Data analysis}

Subject responses on the yes/no questions were analyzed first. Chi-square was used to analyze answer frequencies for the four junctures of awakening. Ratings for intensity of the four conditions were then compared. Since the ratings were on Likert-type scales, which are ordinal, non-parametric statistics were used. A Friedman test was employed to compare the ratings among the four conditions. And, a Wilcoxon signed rank test along with Bonferroni's correction, were used to make post hoc comparisons.

Bivariate Spearman's rank correlation analyzes were first conducted to identify the variables that are associated with subjective estimates of sleep depth. In order to identify the experiences that determine the subjective perception of having fallen asleep, a forward stepwise logistic multiple regression was then conducted to identify the predictors for the response to the binary question "did you fall asleep?"

\section{Results}

As expected, the average durations of time for the subjects to reach the four junctures of awakening increased from SEM through to S2+5: they were, respectively, $189.0 \mathrm{~s}, 411.3 \mathrm{~s}, 605.9 \mathrm{~s}$, and $1162.0 \mathrm{~s}$. The frequencies of various subjective experiences are presented in Table 1. Chi-square analyzes show that among the several conditions only Sleep Perception differed. As expected, the perception of having fallen asleep increased throughout the sleep onset period. The Friedman's test - comparing the ratings on different dimensions of subjective experience across the junctures of sleep onset - reveals that most of the ratings (sleep depth, clarity of environmental perception, control over perception, control over thoughts, coherence of

Table 1

Frequencies, percentages, and Chi-square results for the yes/no questions.

\begin{tabular}{|c|c|c|c|c|c|c|c|c|}
\hline \multirow[t]{2}{*}{ Item } & \multicolumn{5}{|c|}{ Juncture of Awakening } & \multirow[t]{2}{*}{$X^{2}$} & \multirow[t]{2}{*}{$\mathrm{df}$} & \multirow[t]{2}{*}{$p$} \\
\hline & $\mathrm{Y} / \mathrm{N}$ & SEM & S1 & S2 & $\mathrm{S} 2+5$ & & & \\
\hline Sleep perception & $\begin{array}{l}\mathrm{Y} \\
\mathrm{N}\end{array}$ & $\begin{array}{l}3(15 \%) \\
7(85 \%)\end{array}$ & $\begin{array}{l}8(40 \%) \\
12(60 \%)\end{array}$ & $\begin{array}{l}9(45 \%) \\
11(55 \%)\end{array}$ & $\begin{array}{l}16(80 \%) \\
4(20 \%)\end{array}$ & 17.37 & 3 & .001 \\
\hline Visual image & $\begin{array}{l}\mathrm{Y} \\
\mathrm{N}\end{array}$ & $\begin{array}{l}6(30 \%) \\
14(70 \%)\end{array}$ & $\begin{array}{l}13(65 \%) \\
7(35 \%)\end{array}$ & $\begin{array}{l}11(55 \%) \\
9(45 \%)\end{array}$ & $\begin{array}{l}11(55 \%) \\
9(45 \%)\end{array}$ & 5.35 & 3 & .148 \\
\hline Auditory perception & $\begin{array}{l}\mathrm{Y} \\
\mathrm{N}\end{array}$ & $\begin{array}{l}10(50 \%) \\
10(50 \%)\end{array}$ & $\begin{array}{l}7(35 \%) \\
13(65 \%)\end{array}$ & $\begin{array}{l}4(20 \%) \\
16(80 \%)\end{array}$ & $\begin{array}{l}4(20 \%) \\
16(80 \%)\end{array}$ & 5.76 & 3 & .124 \\
\hline Other sensory exp. & $\begin{array}{l}\mathrm{Y} \\
\mathrm{N}\end{array}$ & $\begin{array}{l}10(50 \%) \\
10(50 \%)\end{array}$ & $\begin{array}{l}6(30 \%) \\
14(70 \%)\end{array}$ & $\begin{array}{l}4(20 \%) \\
16(80 \%)\end{array}$ & $\begin{array}{l}4(20 \%) \\
16(80 \%)\end{array}$ & 5.71 & 3 & .126 \\
\hline Thinking experience & $\begin{array}{l}\mathrm{Y} \\
\mathrm{N}\end{array}$ & $\begin{array}{l}14(70 \%) \\
6(30 \%)\end{array}$ & $\begin{array}{l}11(55 \%) \\
9(45 \%)\end{array}$ & $\begin{array}{l}9(45 \%) \\
11(55 \%)\end{array}$ & $\begin{array}{l}9(45 \%) \\
11(55 \%)\end{array}$ & 3.37 & 3 & .338 \\
\hline Emotional experience & $\begin{array}{l}\mathrm{Y} \\
\mathrm{N}\end{array}$ & $\begin{array}{l}5(25 \%) \\
15(75 \%)\end{array}$ & $\begin{array}{l}2(10 \%) \\
18(90 \%)\end{array}$ & $\begin{array}{l}5(25 \%) \\
15(75 \%)\end{array}$ & $\begin{array}{l}0(0 \%) \\
20(100 \%)\end{array}$ & 7.06 & 3 & .070 \\
\hline
\end{tabular}


thoughts, logic of thoughts, perceived reality, sense of involvement, and orientation) changed progressively, in step with the appearances of physiological indices of sleep, from SEM through to S2+5. Significant differences, however, occur at different junctures, for different aspects of subjective experience. It appears that most changes in sensory experience occur early in the process; later, only slight changes occurred. Changes in the thinking process also started early, but continued to change significantly even during the latter stages of sleep onset. Orientation and involvement, on the other hand, did not exhibit significant change until after the start of S1, changes which continued throughout the entire process (see Table 2 and Fig. 1 ). Finally, a few aspects of subjective experience did not evince any significant differences at the different junctures. Specific sensory experiences, such as the vividness of visual imagery, the clarity of auditory perception, and emotional intensity, did not significantly differ among the four conditions.

Table 3 presents the Spearman's correlation coefficients among the variables and the subjective estimates of sleep depth. As indicated by the table, significant correlations were found for most of the subjective experience variables, except for vividness of visual imagery, daily-life concerns, and intensity of emotion. All the variables that showed significant correlations were regressed onto Sleep Perception in a stepwise fashion. Logistic regression identified control over thinking process and logic of thinking as the variables that predict sleep perception. These two variables could explain about $66 \%$ of variance in the perception of sleep $\left(X^{2}(2)=54.16, p<.001\right.$; Nagelkerke $R$ square $\left.=.658\right)$. Control over thought processes and logic of thinking could correctly classify $91.7 \%$ of the perception of sleep and $84.1 \%$ of the perception of waking. The overall correct rate was 87.5\% (see Table 4).

\section{Discussion}

This study aims to explore the subjective experience of the sleep onset process and to identify those experiences that are specifically associated with the perception of having fallen asleep. As expected, the perception of falling asleep as well as subjective estimates of sleep depth increased at each of the four junctures of awakening. Just as has been suggested by previous studies, consistent reports of having fallen asleep were not obtained until 5 min after immersion into stage 2 sleep. Most aspects of subjective experience also changed progressively during the course of sleep onset, but at different paces for different domains. The perception of environmental stimuli dropped significantly from SEM through stage 1 sleep. But after the onset of stage 2, there was little further decline. Thought process was also shown to degenerate progressively during the course of sleep onset. Levels of control, coherence, and logic of thought declined, from the start of SEM, but significant changes did not appear until the start of stage 2 sleep; decline continued even more after the subject began to sleep soundly. Orientation and perceived reality, on the other hand, showed no significant change from SEM to stage $1 \mathrm{sleep}$, but did change significantly after the inception of stage 2 . In other words, significant change did not appear until the latter stages of sleep onset. Emotional intensity was low from the start and evinced little difference at any of the awakening junctures. These

Table 2

Means, standard deviations (SDs), and the results of Friedman's test comparing subjective experiences among different junctures of awakening, and post hoc tests with Wilcoxon signed rank test.

\begin{tabular}{|c|c|c|c|c|c|c|c|c|c|c|}
\hline \multirow[t]{2}{*}{ Variable } & \multicolumn{2}{|c|}{$\operatorname{SEM}(\mathrm{A})$} & \multicolumn{2}{|l|}{$\mathrm{S} 1(\mathrm{~B})$} & \multicolumn{2}{|l|}{$\mathrm{S} 2(\mathrm{C})$} & \multicolumn{2}{|c|}{$\mathrm{S} 2+5(\mathrm{D})$} & \multirow[t]{2}{*}{$X^{2}$} & \multirow[t]{2}{*}{ Post hoc } \\
\hline & Mean & SD & Mean & SD & Mean & SD & Mean & SD & & \\
\hline \multicolumn{11}{|l|}{ Perception of Sleep } \\
\hline Depth of Sleep & 1.55 & 1.32 & 2.23 & 1.07 & 2.80 & .97 & 3.40 & .98 & $33.06^{* * *}$ & $A<B<C<D$ \\
\hline \multicolumn{11}{|l|}{ Sensation and perception } \\
\hline Clarity of Environmental Perception & 3.35 & 1.50 & 2.00 & 1.42 & 1.68 & 1.47 & 1.05 & 1.00 & $28.50^{* * *}$ & $A>B=C=D$ \\
\hline Vividness of Visual Image & .90 & 1.68 & 1.80 & 1.64 & 1.15 & 1.46 & 1.15 & 1.39 & 4.61 & \\
\hline Clarity of Auditory Perception & 1.09 & 1.79 & .75 & 1.48 & .53 & 1.19 & .20 & .52 & 4.63 & \\
\hline Other Sensory Experiences & 1.43 & 1.93 & 1.20 & 1.94 & .60 & 1.50 & .60 & 1.27 & 4.18 & \\
\hline Control over Perception & 2.90 & 1.86 & 2.33 & 1.59 & 1.70 & 1.45 & .83 & 1.39 & $17.16^{* *}$ & $A=B=C>D$ \\
\hline \multicolumn{11}{|l|}{ Thinking processes } \\
\hline Control over Thinking Process & 3.40 & 1.70 & 2.25 & 1.74 & 1.33 & 1.26 & 63 & .81 & $30.85^{* * *}$ & $A=B, A>C>D, B=C>D$ \\
\hline Coherence of Thinking Process & 2.75 & 2.07 & 1.53 & 1.76 & .78 & 1.32 & .40 & .88 & $17.57^{* *}$ & $A=B>C, A>D, B=D, C=D$ \\
\hline Logic of Thinking Process & 3.35 & 2.03 & 1.90 & 2.10 & 1.30 & 1.75 & 60 & 1.05 & $20.98^{* * *}$ & $A=B=C, A>D, B>D, C=D$ \\
\hline \multicolumn{11}{|l|}{ Orientation and involvement } \\
\hline Perceived Reality & 3.70 & 1.59 & 3.43 & 1.04 & 2.43 & 1.52 & 2.05 & 1.64 & $21.57^{* * *}$ & $A=B>C=D$ \\
\hline Daily-Life Concerns & 2.20 & 2.19 & 2.90 & 1.68 & 2.45 & 2.09 & 1.65 & 1.84 & $8.05^{*}$ & $A=B=C, A=D, B>D, C=D$ \\
\hline Here-and-Now Experiences & 2.25 & 2.40 & 2.50 & 2.06 & 1.60 & 1.88 & .85 & 1.53 & $12.59^{* *}$ & $A=B=C, A=D, B>\mathrm{D}, C=D$ \\
\hline Sense of Involvement & 3.95 & 1.54 & 3.10 & 1.97 & 2.48 & 2.07 & 1.68 & 1.76 & $15.07^{* *}$ & $A=B, A>C=D, B=C=D$ \\
\hline Orientation & 4.05 & 1.70 & 3.33 & 1.78 & 2.33 & 1.89 & 1.25 & 1.55 & $34.52^{* * *}$ & $A=B>C>D$ \\
\hline \multicolumn{11}{|l|}{ Emotion } \\
\hline Intensity of Emotion & .73 & 1.33 & .48 & 1.27 & .45 & 1.05 & 0 & 0 & 7.15 & \\
\hline
\end{tabular}

${ }^{*} p<.05$.

** $p<.01$.

$p<.001$. 
(A) Perception of Sleep

Depth of Sleep

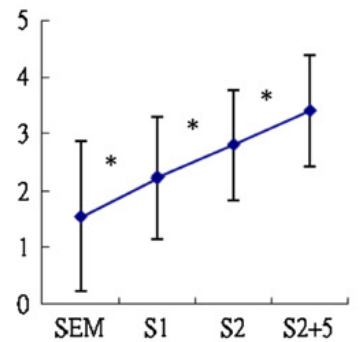

(B) Perceptual Experience

Clearness of Environmental Perception

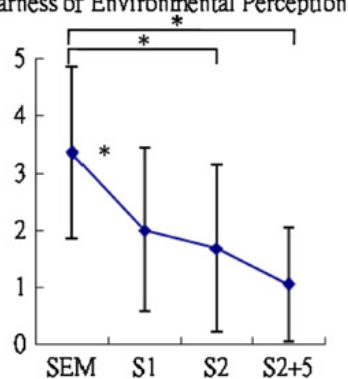

(C) Thinking Process

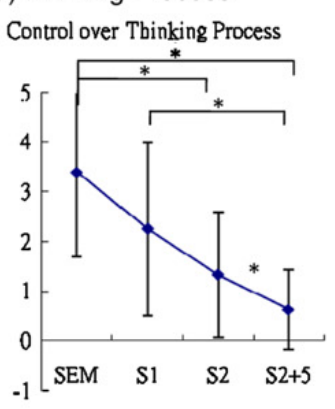

Coberence of Thinking Process

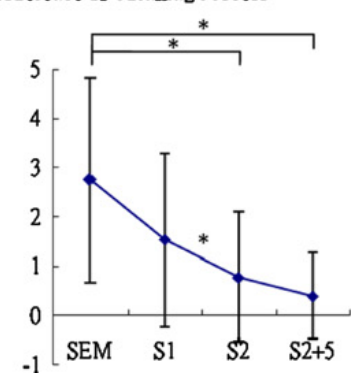

(D) Orientation \& Involvement

Here-and-Now Experience

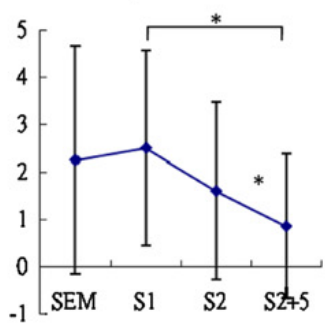

Control over Perception

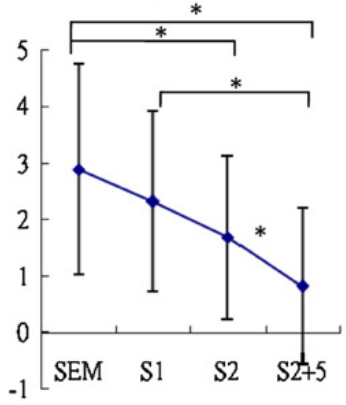

Logic of Thinking Process

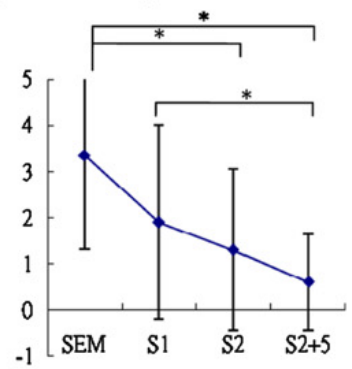

Sense of Involvement

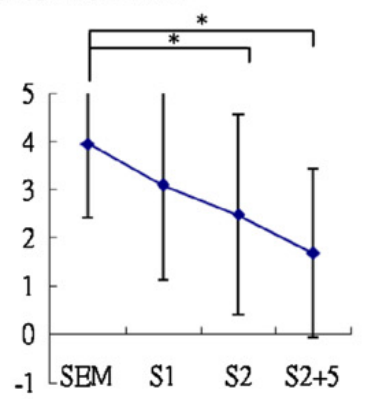

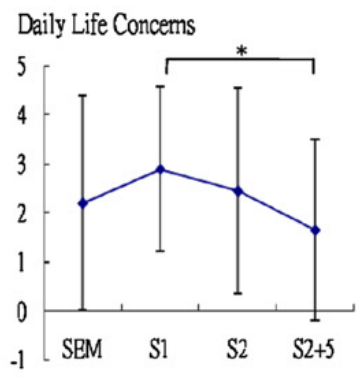

Perceived Reality

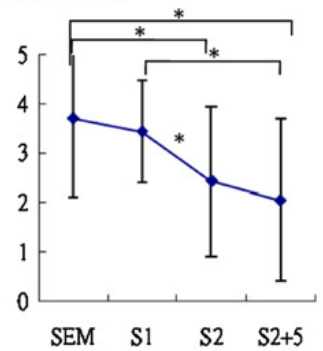

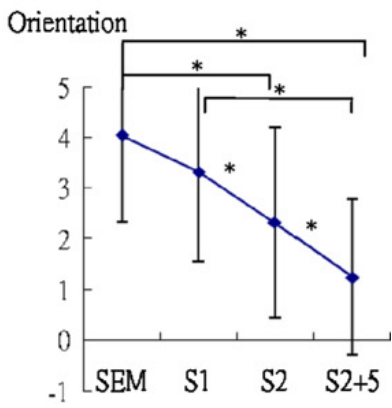

Fig. 1. The ratings on subjective experiences with statistically significant changes over the four junctures (SEM: slow eye movement, S1: stage 1 sleep, S2: stage 2 sleep, and S2+5: 5 min of stable stage 2 sleep) during sleep onset period. Asterisk represents significant difference on Wilcoxon signed rank test with Bonferroni's correction.

findings are consistent with previous studies that revealed significant change in sensory and thought process during sleep onset, while emotional experiences maintained a low intensity throughout (e.g., Foulkes \& Vogel, 1965; Gibson et al., 1982; Hori, Hayashi, \& Hibino, 1992; Hori, Hayashi, \& Morikawa, 1991).

This study's most significant finding is that control over the thinking process is the most prominent subjective experience that is associated with the judgment of having fallen asleep. Thought logic was also identified as a predictor for falling asleep. In addition, our study showed that although sensory processing decrease and thinking process degeneration began early in sleep onset, degeneration continued after immersion into light sleep and more stable sleep. But perception of environmental stimuli showed relatively less diminution. And, degree of orientation was not significantly affected until after stage 2 sleep had been achieved.

Our results may help explain the findings of previous studies which reveal that subjects did not perceive sleep onset until after stable, stage 2 sleep had been achieved. As mentioned above, reports of having slept were more closely associated with 
Table 3

Spearman correlation coefficients among different domains of subjective experience with subjective estimates of depth of sleep.

\begin{tabular}{|c|c|c|}
\hline & Depth of sleep & $p$ \\
\hline \multicolumn{3}{|l|}{ Experiences of sensation and perception } \\
\hline Clarity of Environmental Perception & $-.596^{* * *}$ & $<.001$ \\
\hline Vividness of Visual Image & .170 & .131 \\
\hline Clarity of auditory perception & $-.235^{*}$ & .036 \\
\hline Other Sensory Experiences & -.208 & .064 \\
\hline Control over Perception & $-.583^{* * *}$ & $<.001$ \\
\hline \multicolumn{3}{|l|}{ Thinking processes } \\
\hline Control over Thinking Process & $-.685^{* * *}$ & $<.001$ \\
\hline Coherence of Thinking Process & $-.527^{* * *}$ & $<.001$ \\
\hline Logic of Thinking Process & $-.605^{* * *}$ & $<.001$ \\
\hline \multicolumn{3}{|l|}{ Orientation and Involvement } \\
\hline Perceived Reality & $-.502^{* * *}$ & $<.001$ \\
\hline Daily-Life Concerns & -.184 & .102 \\
\hline Here-and-Now Experiences & $-.277^{*}$ & .013 \\
\hline Sense of Involvement & $-.305^{* *}$ & .006 \\
\hline Orientation & $-.625^{* * *}$ & $<.001$ \\
\hline \multicolumn{3}{|l|}{ Emotion } \\
\hline Intensity of Emotion & $-.251^{*}$ & .025 \\
\hline
\end{tabular}

**** Correlation is significant at the .001 level (2-tailed).

** Correlation is significant at the .01 level (2-tailed).

Correlation is significant at the .05 level (2-tailed).

Table 4

The percentage of correct prediction of perceived sleep with the predictors identified using logistic multiple regression.

\begin{tabular}{|c|c|c|c|c|}
\hline & \multirow[t]{2}{*}{ Observed } & \multicolumn{3}{|c|}{ Predicted } \\
\hline & & Awake & Asleep & Percentage correct \\
\hline \multirow[t]{3}{*}{ Model 1} & Awake & 37 & 7 & 84.1 \\
\hline & Asleep & 5 & 31 & 86.1 \\
\hline & Overall percentage & & & 85.0 \\
\hline \multirow[t]{3}{*}{ Model 2} & Awake & 37 & 7 & 84.1 \\
\hline & Asleep & 3 & 33 & 91.7 \\
\hline & Overall percentage & & & 87.5 \\
\hline
\end{tabular}

the occurrence of stage 2 sleep than with stage 1 sleep. Perception of sleep was previously reported to be related to substantially diminished responsivity to visual and auditory stimuli (Agnew \& Webb, 1972). But Bonnet (1986) demonstrated that although the auditory threshold increased soon after the appearance of the sleep spindle, perceptions of having fallen asleep were not reported until several minutes later. Bonnet's findings are in line with our results, that the perception of sleep onset is more associated with deteriorating thought processes than with perception of external stimuli. One might perceive oneself as being awake, even after the perception of environmental stimuli abates. What seems to be required for the perception of having fallen asleep is substantial loss of control over the thought process along with deterioration of logical reasoning, phenomena that obtain after one enters a period of sustained stage 2 sleep.

As Rechtschaffen (1994) stated, "there are separate effector mechanisms that control the different behavioral conditions that, when considered together, constitute 'sleep'." Our results also support the finding that sleep onset is not a single process; rather, it is parallel processes that comprise multiple components. Changes in different aspects of subjective experience may reflect different underlying mechanisms. The different mechanisms may operate at different rates, thereby corresponding to differential rates of change in subjective experience. Some of the mechanisms may be reflected in the physiological phenomenon that we use to define sleep onset or sleep stages, while others may not. Previous studies have shown that the decline in EEG alpha activity is associated with the subjective report of loss of awareness of the environment (Davis et al., 1937); this is consistent with our findings that the onset of stage 1 sleep is associated with a decline in perception of environmental stimuli. A recent study also showed that the clarity of mental content and controllability of thought both diminish after the onset of stage 2 sleep (Weigand, Michael, \& Schulz, 2007). In our study, control over thinking was found to continue to decline throughout stage 1 and stage 2 sleep, and orientation and involvement were found to decrease after the inception of stage 2 sleep.

Recent studies have also combined EEG and brain imaging techniques in order to explore changes in region-specific brain activity during sleep. The findings obtained from these studies suggest a global decrease in cerebral and thalamic activity during non-rapid eye movement (NREM) sleep. But the specific brain regions identified as responsible for the changes varied somewhat. Generally speaking though, light sleep was associated with decreased activity in the frontal and parietal areas of 
the cortex and in the thalamus. Deep sleep is characterized by a further decrease in activity in these areas, as well as within the basal ganglia (e.g., Balkin et al., 2002; Braun et al., 1997, 1998; Finelli, Baumann, Borbély, \& Achermann, 2000; Kjaer, Nowak, \& Lou, 2002; Maquet, 2000; Nofzinger, Mintun, Wiseman, Kupfer, \& Moore, 1997; Nofzinger et al., 2002; Peigneux et al., 2001). As for stage 1 sleep, Czisch and his colleagues reported fMRI indications of reduced activation in both the auditory and visual cortex in response to auditory stimuli, as demonstrated by a decrease in the blood-oxygenation (Czisch et al., 2002). Also concerning stage 1 sleep, Kaufmann and colleagues' (2006) fMRI studies indicated decreased activation in the thalamic and cingulate structures, other limbic areas, frontal lobes, occipital lobes, temporal lobes, and the insula. These changes may be responsible for a diminution of sensory and thought processes after achieving stage 1 sleep. Stage 2 sleep, on the other hand, was associated with decreased activity in the thalamic and hypothalamic regions, cingulate cortex, right insula and adjacent regions of the temporal lobe, the inferior parietal lobule, as well as the inferior and middle frontal gyri (Kaufmann et al., 2006). These studies when coupled with our findings suggest that diminution of activity in these areas may be responsible for the loss of orientation and self awareness that occurs in stage 2 sleep. Unfortunately though, no detailed subjective experiences were assessed in these brain imaging studies. Knowledge of the relevant neural correlates of these subjective experiences must await future studies.

It should perhaps be noted that the changes in degree of control over and in the logic of thought documented here are not necessarily sustained throughout the entirety of sleep. Several recent comparisons of waking and dream thought have motivated a refinement of prior distinctions: neither, it seems, is dream cognition as inherently deficient in the ways that some have argued, nor is waking cognition as proficient. According to a moderate revision of the distinction, dream thought should not be understood monolithically (Kahn \& Hobson, 2005). For example, there appear to be two distinct types: one employs context logic, which reasons from premises; the other, state logic (metacognition), which reasons about premises. It is only the latter that is absent in the dream state. According to a more robust revision of the distinction, dreaming and waking cognition do not differ qualitatively (Kahan, LaBerge, Levitan, \& Zimbardo, 1997). Reflective awareness and other metacognitive experiences might well be more common in dream cognition than is typically believed; that such experiences are seldom reported might be more a reflection of methodological artifact than of actual dream experience. Possible differences between moderate and more robust revisions of the distinction between waking and dream thought need not be adjudicated here. It need only be pointed out that both sets of studies suggest that some measure of what is lost when subjects perceive the onset of sleep is later recovered when dream cognition commences.

A possible limitation of the current study is that it was conducted on daytime naps rather than nocturnal sleep. It is perhaps arguable that correlations between subjective experiences of sleep onset and physiological indices of sleep onset differ, depending upon whether one is napping or engaged in nighttime sleep. Although such a view is neither motivated by current theory nor by empirical evidence, to rule out this possibility further, supplementary studies should be carried out.

\section{References}

Agnew, J. H. W., \& Webb, W. B. (1972). Measurement of sleep onset by EEG criteria. American Journal of EEG Technology, 12, $127-134$.

Amrhein, C., \& Schulz, H. (2000). Self reports after wakening - a contribution to sleep perception. Somnologie, 4(2), 61-67.

Anliker, J. (1966). Simultaneous changes in visual separation threshold and voltage of cortical alpha rhythm. Science, 153, $316-318$.

Azekawa, T., Sei, H., \& Morita, Y. (1990). Continuous alteration of EEG activity in human sleep onset. Sleep Research, $19,7$.

Balkin, T. J., Braun, A. R., Wesensten, N. J., Jeffries, K., Varga, M., Baldwin, P., et al (2002). The process of awakening: A PET study of regional brain activity patterns mediating the re-establishment of alertness and consciousness. Brain, 125(10), 2308-2319.

Barrett, J., Lack, L., \& Morris, M. (1993). The sleep-evoked decrease of body temperature. Sleep, 16(02), 93-99.

Bonnet, M. H. (1986). Auditory thresholds during continuing sleep. Biological Psychology, 22(1), 3-10.

Braun, A. R., Balkin, T. J., Wesensten, N. J., Carson, R. E., Varga, M., Baldwin, P., et al (1997). Regional cerebral blood flow throughout the sleep-wake cycle. An $\mathrm{H}_{2}{ }^{(15)}$ O PET study. Brain, 120, 1173-1197.

Braun, A. R., Balkin, T. J., Wesensten, N. J., Gwadry, F., Carson, R. E., Varga, M., et al (1998). Dissociated pattern of activity in visual cortices and their projections during human rapid eye movement sleep. Science, 279(5347), 91-95.

Campbell, K., Bell, I., \& Bastien, C. (1992). Evoked potential measures of information processing during natural sleep. In R. J. Broughton \& R. D. Ogilvie (Eds.), Sleep arousal and performance (pp. 88-116). Boston, MA: Birkhauser.

Colrain, I. M., Trinder, J., Fraser, G., \& Wilson, G. V. (1987). Ventilation during sleep onset. Journal of Applied Physiology, 63, 2067-2074.

Czisch, M., Wetter, T. C., Kaufmann, C., Pollmacher, T., Holsboer, F., \& Auer, D. P. (2002). Altered processing of acoustic stimuli during sleep: Reduced auditory activation and visual deactivation detected by a combined fMRI/EEG study. NeuroImage, 16, 251-258.

Davis, H., Davis, P. A., Loomis, A. L., Harvey, E. N., \& Hobart, G. (1937). Changes in human brain potentials during the onset of sleep. Science, 86, 448-450.

Davis, H., Davis, P. A., Loomis, A. L., Harvey, E. N., \& Hobart, G. (1938). Human brain potentials during the onset of sleep. Journal of Neurophysiology, 1, 24-38.

De Gennaro, L., Ferrara, M., Ferlazzo, F., \& Bertini, M. (2000). Slow eye movements and EEG power spectra during wake-sleep transition. Clinical Neurophysiology, 111(12), 2107-2115.

Finelli, L. A., Baumann, H., Borbély, A. A., \& Achermann, P. (2000). Dual electroencephalogram markers of human sleep homeostasis: Correlation between theta activity in waking and slow-wave activity in sleep. Neuroscience, 101(3), 523-529.

Foulkes, D., \& Vogel, G. (1965). Mental activity at sleep onset. Journal of Abnormal Psychology, 70, $231-243$.

Gibson, E., Perry, F., Redington, D., \& Kamiya, J. (1982). Discrimination of sleep onset stages: Behavioral responses and verbal reports. Perceptual and Motor Skills, 55(3 Pt 2), 1023-1037.

Harsh, J., Voss, U., Hull, J., Schrepfer, S., \& Badia, P. (1994). ERP and behavioral changes during the wake/sleep transition. Psychophysiology, 31(3), $244-252$.

Hori, T. (1985). Spatiotemporal changes of EEG activity during waking-sleeping transition period. International Journal of Neuroscience, 27(1), 101-114.

Hori, T., Hayashi, M., \& Hibino, K. (1992). An EEG study of the hypnagogic hallucinatory experience. International Journal of Psychology, $27,420$.

Hori, T., Hayashi, M., \& Morikawa, T. (1991). Changes of EEG patterns and reaction time during hypnagogic state. Sleep Research, $20,20$.

Hori, T., Hayashi, M., \& Morikawa, T. (1994). Topographical EEG changes and the hypnagogic experience. In R. D. Ogilvie \& J. R. Harsh (Eds.), Sleep onset (pp. 237-253). Washington, DC: American Psychological Association.

Jacobson, A., Kales, A., Lehmann, D., \& Hoedemaker, F. S. (1964). Muscle tonus in human subjects during sleep and dreaming. Experimental Neurology, 10(5), $418-424$.

Johnson, L. C. (1970). A psychophysiology for all states. Psychophysiology, 6, 501-516. 
Kahan, T., LaBerge, S., Levitan, L., \& Zimbardo, P. (1997). Similarities and differences between dreaming and waking cognition: An exploratory study. Consciousness and Cognition, 6, 132-147.

Kahn, D., \& Hobson, J. A. (2005). State-dependent thinking: A comparison of waking and dreaming thought. Consciousness and Cognition, $14,429-438$.

Kaufmann, C., Wehrle, R., Wetter, T. C., Holsboer, F., Auer, D. P., Pollmächer, T., et al (2006). Brain activation and hypothalamic functional connectivity during human non-rapid eye movement sleep: An EEG/fMRI study. Brain, 129(3), 655-667.

Kjaer, T. W., Nowak, M., \& Lou, H. C. (2002). Reflective self-awareness and conscious states: PET evidence for a common midline parietofrontal core. NeuroImage, 17(2), 1080-1086.

Krauchi, K., Cajochen, C., Werth, E., \& Wirz-Justice, A. (2000). Functional link between distal vasodilation and sleep-onset latency. The American Journal of Physiology - Regulatory, Integrative and Comparative Physiology, 278(3), R741-748.

Lehmann, D., Grass, P., \& Meier, B. (1995). Spontaneous conscious covert cognition states and brain electric spectral states in canonical correlations. International Journal of Psychophysiology, 19, 41-52.

Litchman, J. (1974). Mentals EMG in human sleep and wakefulness. Chicago: University of Chicago.

Maquet, P. (2000). Functional neuroimaging of normal human sleep by positron emission tomography. Journal of Sleep Research, 9(3), $207-231$.

Merica, H., Fortune, R. D., \& Gaillard, J. M. (1991). Hemispheric temporal organization during the onset of sleep in normal subjects. In M. G. Terzano, P. L. Halasz, \& A. C. Declerck (Eds.), Phasic events and dynamic organization of sleep. New York: Raven Press.

Naifeh, K. H., \& Kamiya, J. (1981). The nature of respiratory changes associated with sleep onset. Sleep, 4(1), 49-59.

Nofzinger, E. A., Buysse, D. J., Miewald, J. M., Meltzer, C. C., Price, J. C., Sembrat, R. C., et al (2002). Human regional cerebral glucose metabolism during nonrapid eye movement sleep in relation to waking. Brain, 125(5), 1105-1115.

Nofzinger, E. A., Mintun, M. A., Wiseman, M., Kupfer, D. J., \& Moore, R. Y. (1997). Forebrain activation in REM sleep: An FDG PET study. Brain Research, 770(12), 192-201.

Ogilvie, R. D., \& Simons, I. (1992). Falling asleep and waking up: A comparison of EEG spectra. In R. J. Broughton \& R. D. Ogilvie (Eds.), Sleep, arousal and performance (pp. 73-87). Boston: Birkhäuser.

Ogilvie, R. D., Simons, I. A., Kuderian, R. H., MacDonald, T., \& Rustenburg, J. (1991). Behavioral, event-related potential, and EEG/FFT changes at sleep onset. Psychophysiology, 28(1), 54-64.

Ogilvie, R. D., \& Wilkinson, R. T. (1984). The detection of sleep onset: Behavioral and physiological convergence. Psychophysiology, 21(5), 510-520.

Ogilvie, R. D., \& Wilkinson, R. T. (1988). Behavioral versus EEG-based monitoring of all-night sleep/wake patterns. Sleep, 11(02), $139-155$.

Ogilvie, R. D., Wilkinson, R. T., \& Allison, S. (1989). The detection of sleep onset: Behavioral, physiological, and subjective convergence. Sleep, 12(5), 458-474.

Peigneux, P., Salmon, E., Garraux, G., Laureys, S., Willems, S., \& Dujardin, K. (2001). Neural and cognitive bases of upper limb apraxia in corticobasal degeneration. Neurology, 57(7), 1259-1268.

Porte, H. S. (2004). Slow horizontal eye movement at human sleep onset. Journal of Sleep Research, 13, $239-249$.

Rechtschaffen, A. (1994). Sleep onset: Conceptual issues. In R. D. Ogilvie \& J. R. Harsh (Eds.), Sleep onset (pp. 3-17). Washington, DC: American Psychological Association.

Rechtschaffen, A., \& Kales, A. (1968). A manual of standardized terminology, techniques and scoring for sleep stages of human subjects. Los Angeles: University of California.

Rowley, J. T., Stickgold, R., \& Hobson, J. A. (1998). Eyelid movements and mental activity at sleep onset. Consciousness and Cognition, 7(1), 67-84.

Schacter, D. L. (1976). The hypnagogic state: A critical review of the literature. Psychological Bulletin, 83(3), 452-481.

Sewitch, D. E. (1984). The perceptual uncertainty of having slept: The inability to discriminate electroencephalographic sleep from wakefulness. Psychophysiology, 21(3), 243-259.

Simon, C. W., \& Emmons, W. H. (1956). Responses to material presented during various levels of sleep. Journal of Experimental Psychology, 51, 89-97.

Tsuno, N., Shigeta, M., Hyoki, K., Kinoshita, T., Ushijima, S., Faber, P. L., et al (2002). Spatial organization of EEG activity from alertness to sleep stage 2 in old and younger subjects. Journal of Sleep Research, 11(1), 43-51.

Vogel, G., Barrowclough, B., \& Giesler, D. (1972). Limited discriminability of REM and sleep onset reports and its psychiatric implications. Archives of General Psychiatry, 26, 449-455.

Vogel, G., Foulkes, D., \& Trosman, H. (1966). Ego functions and dreaming during sleep onset. Archives of General Psychiatry, 14, $238-248$.

Wackermann, J., Pütz, P., Büchi, S., Strauch, I., \& Lehmann, D. (2002). Brain electrical activity and subjective experience during altered states of consciousness: Ganzfeld and hypnagogic states. International Journal of Psychophysiology, 46, 123-146.

Webb, W. B. (1980). The natural onset of sleep. In B. A. L. Popoviciu \& G. Badia (Eds.), Sleep 1978. Fourth European congress on sleep research (pp. 19-23). Tirgu-Mures, Rumania, and Basel, Switzerland: S. Kager.

Wehr, T. A. (1990). Effects of wakefulness and sleep on depression and mania. In J. Mountplaisir \& R. Godbout (Eds.), Sleep and biological rhythms: Basic mechanisms and applications to psychiatry (pp. 42-86). Oxford: Oxford University Press.

Weigand, D., Michael, L., \& Schulz, H. (2007). When sleep is perceived as wakefulness: An experimental study on state perception during physiological sleep. Journal of Sleep Research, 16(4), 346-353. 